\title{
The Biometeorology of COVID-19: A Novel Therapeutic Strategy?
}

\author{
Elena Cantone ${ }^{1, *}$, Mario Gamerra ${ }^{2}$
}

\section{AUTHOR AFFILIATIONS}

${ }^{1}$ Department of Neuroscience, Reproductive and Odontostomatological Sciences - ENT section, University “Federico II”, Naples, Italy

${ }^{2}$ ASL NA3 Sud Distretto 56 - U.O.A.R, Italy

* Corresponding author: Department of Neuroscience, Reproductive and Odontostomatological Sciences - ENT section, University

“Federico II", Naples, Italy. Via Pansini, 5, 80131, Naples, Italy; e-mail: elena.cantone@unina.it; elenacantone@libero.it

Received: 16 August 2020

Accepted: 2 October 2020

Published online: 22 December 2020

Acta Medica (Hradec Králové) 2020; 63(4): 202-204

https://doi.org/10.14712/18059694.2020.65

(c) 2020 The Authors. This is an open-access article distributed under the terms of the Creative Commons Attribution License (http://creativecommons.org/licenses/by/4.0), which permits unrestricted use, distribution, and reproduction in any medium, provided the original author and source are credited. 


\section{BRIEF COMMUNICATION}

In December 2019 a novel coronavirus, SARS-CoV-2, genetically related to SARS-CoV, was first reported in Wuhan, China. The rapid spread of the virus, that has affected more and more countries, and its substantial morbidity and mortality has prompted the World Health Organization to declare the coronavirus disease (COVID 19) outbreak a global pandemic (1).

Following the spread of the virus, based on the median daily reproduction number $\left(R_{t}\right)$, it was immediately clear, as confirmed by recent biometeorological studies, that Coronavirus was initially spreading mainly in the corridor between $30^{\circ}$ and $50^{\circ}$ of latitude, China, Japan, Southern Korea, Iran, Northern Italy, characterized by a temperate climate. Furthermore, some countries very close to China such as Vietnam, Cambodia or Thailand were not suffering from the infection as massively as in other countries, for example the Northern Italy. Likely, in the initial phase of the spread the most affected areas of Australia and Africa were precisely those with a temperate climate such as the new west south and the city of Victoria and the South Africa (1). Interestingly, climatic factors as latitude, temperature, and humidity seem to strongly influence the propagation of the COVID $19(2,3)$.

To better understand epidemiological and spread characteristics of SARS-COV-2, the best model currently available is the human influenza virus. Human influenza incidence is characterized by a strong seasonal cycle in temperate regions depending on environmental factors that may play a role in the transmission process. For instance, previous literature data have examined temperature and humidity as factors associated with influenza propagation $(4,5)$.

According to Wang et al. at low temperatures the influenza virus is more stable and the respiratory droplets, which represent the containers of the viruses, persist suspended in the dry air for longer (3). In addition, the dry weather could weaken the immunity of the host and make them more vulnerable to the virus $(1,3)$. Again, some epidemiological studies have demonstrated that low levels of specific humidity are associated with the onset of pandemic and epidemic influenza in the North America. As a consequence, high temperature and high humidity may reduce the transmission of influenza (4). Hence, survival and transmission of influenza viruses are favored by low specific humidity conditions in temperate regions, thus causing annual winter epidemics. However, this relationship is inconsistent in tropical and subtropical regions where epidemics often occur during the rainy season and are transmitted all year round without a well-defined season. This could be due to the strong variations in temperature and humidity between day and night, typical of tropical climates, which make the climatic conditions unstable $(4,5)$.

All these mechanisms are also likely to apply to COVID-19 transmission. SARS-COV-2, as well as influenza virus and other viruses, seems to use humans to survive and, above all it uses humans as vectors to reach regions with more favorable climate. Actually, following the number of contagions over time, epidemiologists have observed that the SARS-COV-2 moved from East to West in search of conditions of humidity, temperature and atmospheric pressure suitable for its survival. Indeed, SARSCOV-2 would survive better in a climate between 5 and 11 degrees and with humidity between $47 \%$ and $79 \%$ (6). Obviously, once the virus has spread, it tends to expand globally, that's why, at present, the involvement of the infection is almost global.

Humidity, temperature and atmospheric pressure are factors on which the dew point depends. The dew point indicates the temperature at which the relative humidity of the air reaches $100 \%$ saturation. Relative humidity represents the percentage of water vapor in the air at a given temperature, that changes when the air temperature changes. A higher dew point indicates a higher moisture content for the air. The air is saturated when the dew point corresponds to the air temperature. The dew point never exceeds the air temperature. The lower the dew point, the less water, in the form of vapor, can be contained in the air and vice versa. When temperatures drop, relative humidity increases. High relative humidity of the air occurs when the air temperature approaches the dew point value.

Sterling in the 1985 described the optimal relative humidity range, in which most viruses survive. In particular, the influenza virus survives better in aerosols of low relative humidity (<50\%). Some viruses prefer a high relative humidity, whereas some other viruses a low relative humidity, so there is an average humidity range between $50 \%$ and $70 \%$ in which the viral population is minimal (7). The above would lead us to think, optimistically, that the transmission of the infection will decrease with the increase in temperatures and humidity typical of the late spring and summer in temperate climate countries.

However, a crucial point is the progressive changing of the climate in countries with a temperate climate. This climatic transformation depending on the Earth's spin axis drift, determines strong thermal excursions which destabilize the climate and could favor the survival of the virus.

Recently, NASA scientists have defined three main processes responsible for the Earth's spin axis drift, among which the melting of the global cryosphere, in particular Greenland, over the course of the 20th century is one of the most important (8). The melting of the glaciers could be the consequence of climate changes.

According to the Intergovernmental Panel on Climate Change (IPCC), the United Nations climate committee, anthropogenic warming has led to major climate changes in climate zones. In particular, it led to an increase in dry climates and a decrease in polar climates. Furthermore, continuous warming should lead to new warm climates in tropical regions and move climatic zones to medium-high latitudes and to regions with higher altitudes. Climate change has always influenced the Earth, butuntil a few centuriesago they were slow, related to known natural phenomena such as the oscillations of the Earth's axis and volcanic phenomena. However, these changes have been much more rapid in recent years. According to the report of the IPCC on Earth-climateinteractions, the influence of man on climate change is undoubted and current climate change is such as to compromise the adaptability of the living being (9).

Furthermore, researchers reported that the alarm is particularly serious for Italy, which is heating up faster 
than the global average of the planet. In particular, the warming of global Italy would seem to be one and a half times that of the Earth's average and twice that of the entire globe (10). The storms and floods that have occurred in Italy in recent years are clear evidence of these climate changes. In addition, not by chance in Italy SARS-COV-2 has spread particularly in the North of the country where the cities with the highest industrial pollution are concentrated (Bergamo, Milano, Brescia).

Consequently, an immediate intervention on environmental policy through massive environmental operations against pollution and the promotion of alternative energies are mandatory also to prevent pandemics such as that of COVID-19.

Certainly, it is not possible, in the short term, to change the global climate, but since environmental conditions can vary substantially between indoor and outdoor $(4,5)$, it is absolutely possible to change the indoor climate by changing the humidity and temperature, especially in crowded places, workplaces, schools, hospitals especially intensive care units but also at home. This type of strategy could also benefit in the short term, above all in terms of preventing viral infections and viral spread.

Unfortunately, while outdoor relative humidity is higher in winter, indoor relative humidity is much drier due to heating. Hence, exposure to cold outside air and indoor dry air increases, again, the transmission of the virus. On the contrary, incidence of viral acute respiratory diseases seems to be lower among occupants of building with low humidity levels. Indeed, previous studies demonstrated significant reduction in respiratory infections among occupants of humidified buildings (7).

In healthy people and in physiological conditions, inhaled air reaches approximately $31-34{ }^{\circ} \mathrm{C}$ and $90-100 \%$ relative humidity by the time it leaves the nasopharynx. In the respiratory airways, cold air dries airflows through the respiratory tract and inhibits mucociliary clearance. In addition, at low humidity the respiratory droplets evaporate, decrease their size and increase the ability to travel further. These phenomena increase again the possibility of viral transmission (7).

According to Sterling, the potential cause of the reduction in respiratory infections is probably due to an increase in the settling rate of aerosols at high humidity (7). So, a therapeutic strategy against Covid-19 could be creating in the upper and lower respiratory tract conditions of humidity that are unfavorable to the virus. So, from a clinical point of view, humidification of the lower respiratory tract becomes particularly useful in patients hospitalized for pneumonia, especially when oxygen therapy is needed (11).

\section{REFERENCES}

1. Top $100 \mathrm{R}$ resources on Novel COVID-19 Coronavirus (released 12/03/2020). (Accessed Aug 16, 2020, at https://towardsdatascience .com/top-5-r-resources-on-covid-19-coronavirus-1d4c8df6d85f.)

2. Lin S, Wei D, Sun Y, Chen K, et al. Region-specific air pollutants and meteorological parameters influence COVID-19: A study from mainland China. Ecotoxicol Environ Saf 2020; 204: 111035.

3. Wang J, Tang K, Kai F, et al. Temperature and High Humidity Reduce the Transmission of COVID-19 (March 9, 2020). Available at SSRN: https://ssrn.com/abstract=3551767 or http://dx.doi.org/10.2139 /ssrn.3551767.

4. Tamerius JD, Shaman J, Alonso WJ, et al. Environmental predictors of seasonal infuenza epidemics across temperate and tropical climates. PLoS Pathog 2013; 3: e1003194.

5. Tamerius J, Ojeda S, Uejio CK, et al. Influenza transmission during extreme indoor conditions in a low-resource tropical setting. Int $J$ Biometeorol 2017; 4: 613-22.

6. Enhanced model for monitoring zones of increased risk of covid-19 spread. Global virus networ. (released 10/03/2020). (Accessed Aug 16, 2020, at https://gvn.org/enhanced-model-for-monitoring-zonesof-increased-risk-of-covid-19-spread/.)

7. Sterling E M, Arundel A, Sterling T D. 1985. Criteria for human exposure to humidity in occupied buildings. ASHRAE Transactions 1985; 91: 611-22

8. Adhikari S, Caron L, Steinberger B, Reager JT, Ivins ER. What drives 20th century polar motion? Earth and Planetary Science Letters 2018; 50215: 126-32.

9. Jia G, Shevliakova E, Artaxo P, et al. Land-climate interactions. 2019: Land-climate interactions. In: Climate Change and Land: an IPCC special report on climate change, desertification, land degradation, sustainable land management, food security, and greenhouse gas fluxes in terrestrial ecosystems [P.R. Shukla, J. Skea, E. Calvo Buendia, V. Masson-Delmotte, H.-O. Pörtner, D.C. Roberts, P. Zhai, R. Slade, S. Connors, R. van Diemen, M. Ferrat, E. Haughey, S. Luz, S. Neogi, M. Pathak, J. Petzold, J. Portugal Pereira, P. Vyas, E. Huntley, K. Kissick, M, Belkacemi, J. Malley, (eds.)]. In press.

10. Cambiamenti climatici:l'Italia si scalda il doppio rispetto al resto del Pianeta.Greenews.info (released 23/01/2015). (Accessed Aug 16, 2020, at http://www.greenews.info/comunicati-stampa/cambiamenti -climatici-litalia-si-sta-scaldando-il-doppio-rispetto-al-resto-del -pianeta-20150123/.)

11. Lindemann J, Sannwald D, Wiesmiller K. Age-related changes in intranasal air conditioning in the elderly. Laryngoscope 2008; 118 : 1472-5. 